\title{
Airway inflammation in waste handlers exposed to bioaerosols assessed by induced sputum
}

\author{
K.K. Heldal*,\#, A.S. Halstensen*, J. Thorn", W. Eduard*, T.S. Halstensen\#
}

Airway inflammation in waste handlers exposed to bioaerosols assessed by induced sputum. K.K. Heldal, A.S. Halstensen, J. Thorn, W. Eduard, T.S. Halstensen. (C) ERS Journals Ltd 2003.

ABSTRACT: Work-associated lower airway inflammation in waste collectors was examined by induced sputum and correlated with the bioaerosol exposure.

Organic waste collectors $(n=25)$ underwent induced sputum collection and spirometry before work on Monday and the following Thursday. Total cells, cell differentials, interleukin (IL)-8 and eosinophilic cationic protein were determined. Personal full-shift exposure measurements were performed Monday, Tuesday and Wednesday and analysed for total bacteria, fungal spores, endotoxins and $\beta_{(1-3)}$-glucans.

The percentage of neutrophils $(46-58 \%)$ and the IL-8 concentration $\left(1.1-1.4 \mathrm{ng} \cdot \mathrm{mL}^{-1}\right)$ increased from Monday to Thursday. Forced expiratory volume in one second (FEV1) was significantly reduced on Thursday, and the decrease in FEV 1/forced vital capacity correlated with the increase in the percentage of neutrophils. The median exposure to endotoxin (range 7-180 EU $\cdot \mathrm{m}^{-3}$ ) and $\beta_{(1-3)}$-glucan (range 5-220 $\mathrm{ng} \cdot \mathrm{m}^{-3}$ ) was correlated with the increase in IL-8.

Bioaerosol exposure during waste collection induced an inflammatory response in the lower airways, characterised by neutrophils and interleukin-8 secretion, that influenced the lung function. The inflammatory response was related to microbial components in the bioaerosol and was more pronounced for endotoxin than $\beta_{(1-3)}$-glucan exposure. No associations were found for mould spores or bacteria.

Eur Respir J 2003; 21: 641-645.
*National Institute of Occupational Health, Oslo and ${ }^{\#}$ Institute of Oral Biology, University of Oslo, Norway. "Dept of Environmental Medicine, Gothenburg University, Gothenburg, Sweden.

Correspondence: K.K. Heldal

National Institute of Occupational Health

P.O.Box 8149 Dept

0033 Oslo

Norway

Fax: 4723195206

E-mail: kari.heldal@stami.no

Keywords: Bioaerosol exposure

household waste

induced sputum

Received: July 82002

Accepted after revision: October 282002
Collection of source-separated organic waste has introduced new health hazards, predominantly respiratory inflammation, for an increasing number of workers. Bioaerosols generated from decaying organic waste contain bacteria, bacterial and fungal spores, and microbial components like endotoxins and $\beta_{(1-3)}$-glucans that may induce inflammation $[1,2]$. Inhalation of endotoxins induces the influx of neutrophils and the production of pro-inflammatory cytokines and biomarkers, which is reflected in airway fluids. Endotoxins are regarded as the most potent inflammatory component in bioaerosols [3]. However, exposure to endotoxins during waste collection is usually low compared with the "no-effect level" for airway inflammation [2-6]. Yet, increased levels of neutrophils and their product, myeloperoxidase (MPO), in the nasal lavage from waste collectors and compost workers were related to the endotoxin exposure during work $[1,5]$. Animal and human inhalation studies have suggested that $\beta_{(1-3)}$-glucans have inflammatory properties. $\beta_{(1-3)}$-glucans are regarded as a marker of fungal spores, but can also be present in some bacteria and plant material. The response in the airways is different from that induced by inhaled endotoxins. This probably depends on the structure and physical properties of $\beta_{(1-3)}$-glucans [7]. Animal studies have shown that $\beta_{(1-3)}$-glucan exposure causes an eosinophil dominated inflammatory response, which decreases after simultaneous endotoxin exposure [8]. Conversely, in a similar animal model, a single exposure to $\beta_{(1-3)}$-glucans is reported to reduce the inflammatory response to endotoxins, while repeated exposures have induced a synergistic inflammatory effect between $\beta_{(1-3)}$-glucans and endotoxins [7]. These studies suggest that bioaerosol exposure induced inflammatory responses associated with different components in the aerosol with a possible complex interaction between the microorganisms or microbial cell wall components.

In this study, induced sputum was used to assess airway inflammation in waste collectors. Sputum examination has become an important noninvasive method for direct investigation of the degree of lower airway inflammation. At present, this method has proven its feasibility mainly in human challenge studies to reveal mechanisms of asthma and other lung diseases. A few small studies of working populations have also been reported [2,9]. The purpose of this study was to assess the various cell types and mediators of inflammation in the induced sputum of waste collectors and to correlate these findings with the exposure to different components in the bioaerosol generated when collecting household waste.

\section{Material and methods}

\section{Population}

The survey was performed at a waste company in a community near Oslo, in which separation of household waste was implemented in 1997 . The organic waste fraction, mainly consisting of food and garden waste, was stored in closed containers and collected every fortnight. The survey took place in the summers of 1999 and 2000. In total, 25 waste collectors participated voluntary in the survey $(84 \%$ participation rate), of which 22 collected the organic waste and three collected the paper waste fraction of the household waste. The main work tasks for the collectors were emptying containers 
and driving trucks. The workers had been employed for $1.0 \mathrm{yr}$ (median) at the company (range 1-8 yrs). The median age was 32 yrs, range of $17-53$ yrs. Current smokers included $88 \%$ $(n=22)$ of workers, with an arithmetic median tobacco consumption of 11 (range 0-34) pack-yrs. Sixteen waste collectors tested voluntarily for respiratory allergens by the Phadiatop test (fluorescent enzyme immunoassay (FEIA), UniCap system; Pharmacia Diagnostic AB, Uppsala, Sweden). Five of these collectors $(31 \%)$ revealed atopy.

\section{Study design}

Medical examination of the waste collectors was performed at the local hospital. The examination consisted of spirometry and sputum collection before working on Monday morning and before working on the following Thursday morning. The workers were asked not to smoke $1 \mathrm{~h}$ before the medical examination. Personal full-shift exposure was monitored on each day between the medical examinations. All subjects gave their informed consent and the study was approved by the Regional Medical Ethics Board.

\section{Sampling and analysis of exposure}

Inhalable aerosols were collected by personal sampling with two personal aerosol sampler cassettes (inlet $6 \mathrm{~mm}$; National Institute of Occupational Health, Oslo, Norway) simultaneously. One sample was collected on a glass fibre filter (Whatman GF/A; Whatman, Maidstone, MA, USA) and analysed for endotoxins and $\beta_{(1-3)}$-glucans by specific, quantitative, kinetic and chromogenic Limulus amoebocyte-lysate assays [10, 11]. The other sample was collected on a polycarbonate filter with pore size $0.8 \mu \mathrm{m}$ (Poretics; Osmonics, Livermore, MN, USA). In these samples, rod-shaped and spherical bacteria were determined by fluorescence microscopy [12], and spores from fungi and actinomycetes were counted in a scanning electron microscope [13]. The exposure to bacteria was expressed both as total bacteria counted (the sum of spherical, rod-shaped bacteria and actinomycetes spores), as well as the number of actinomycetes spores, spherical bacteria and rod-shaped bacteria separately.

\section{Induced sputum}

The induction procedure of PIN et al. [14] was used with some modifications. After bronchodilatation ( $\beta_{2}$-agonist, $200 \mu \mathrm{g}$ salbutamol inhalation), induction was performed by $7-\mathrm{min}$ inhalation periods of 3 and 5\% hypertonic saline using an ultrasonic nebuliser (DeVilbiss; Sunrise medical, Somerset, PA, USA) following a baseline spirometry. The inhalation was stopped if a sputum sample of good quality was obtained. Spirometry was also performed after the induction periods for safety reasons. If forced expiratory volume in one second (FEV1) decreased $>20 \%$ from the baseline value, the sputum induction was discontinued.

\section{Sputum processing and cell counting}

Samples were processed according to the "plug method" described by PIZZICHINI et al. [15] with some modification. The supernatants after dithiothreitol incubation and centrifugation were added to a protease inhibitor cocktail (soya bean trypsin inhibitor, aprotinin, $\beta_{1}$-antitrypsin, pepstatin A, 1,10 -phenanthroline, ethylene diamine tetra-acetic acid and benzamidine; Sigma, St Louis, MO, USA) and frozen to $-20^{\circ} \mathrm{C}$ until analysis. The total cell count and the cell viability of the cell samples were determined using Trypan blue exclusion $(0.4 \%)$ and a Bürker chamber. Visually identified squamous epithelial cells were excluded from the counts to estimate the total cell concentration. The cell samples were cytocentrifuged and stained with May-Grünwals-Giemsa. Samples were considered adequate if the differential counts contained $<25 \%$ squamous cells. At least 400 nonsquamous cells were counted. Stratified counting was performed on eosinophils and lymphocytes to improve the precision. Thus, percentages of lymphocytes and eosinophils were based on 2,000-3,000 cells. The results were expressed as $10^{6}$ cells $\cdot \mathrm{mL}^{-1}$ sputum or as a percentage of the total nonsquamous epithelial cell count. In the study population, 21 waste collectors delivered adequate sputum samples, 20 of which collected organic waste and one collected paper waste.

\section{Analysis of interleukin-8}

The concentration of interleukin (IL)- 8 was measured by enzyme-linked immunosorbent assay (R\&D Systems, Oxon, UK). Spiking experiments in 21 samples from seven workers with recombinant IL- 8 concentrations of $\geqslant 20 \%$ of the IL- 8 content in the samples, revealed an average of $36 \%$ recovery (range $0-72 \%$ ), suggesting underestimation of IL-8 concentration in sputum. Running the standard curve in several sputum samples revealed individual curves slightly skewed to the right. The average of two standard curves run in sputum samples with low IL-8 concentration was then used to recalculate the IL-8 concentration in all samples. The recovery rose to $65 \%$ (range $0-203 \%$ ). Re-running all statistics revealed slight changes in significance for some of the relationships. However, since it appeared that all workers had an individual sputum-based standard curve, the use of a sputum-based curve on the average of the two workers sputum to calculate the IL- 8 concentrations in all workers, was not more or less correct than using the buffer-based standard curve. In order to compare these results with other published reports, the authors decided to use the data based on the buffer-based standard, but have provided the statistical influence of the tested relationships in the results. The concentrations were expressed as $\mathrm{ng} \cdot \mathrm{mL}^{-1}$. The detection limit was $31 \mathrm{pg} \cdot \mathrm{mL}^{-1}$.

\section{Analysis of eosinophil cationic protein}

Eosinophil cationic protein (ECP) was measured by an FEIA technique (UniCAP ECP FEIA, Pharmacia Diagnostics $\mathrm{AB})$. The concentrations were expressed as $\mathrm{ng} \cdot \mathrm{mL}^{-1}$. The detection limit was $2.0 \mathrm{ng} \cdot \mathrm{mL}^{-1}$.

\section{Spirometry}

A spirometer (Vitalograph 2170; Spirotrac IV, Ennis, Ireland) was used and forced vital capacity (FVC) and the FEV1 were measured according to the American Thoracic Society guidelines [16]. The same trained nurse performed all the tests. The largest FEV1 value was selected and compared with predicted values [17]. Subjects with spirometric airflow limitation were defined as those with a ratio of FEV1/FVC of $<70 \%$ and a FEV $1<80 \%$ of predicted value [18].

\section{Questionnaires}

The participants completed a self-administered questionnaire including questions on respiratory symptoms that they 
had experienced on the day of exposure measurements. This questionnaire had been used previously in investigations of organic dust-related effects [19].

\section{Statistical analysis}

Exposure was estimated for each worker by the median of the exposures measured on Monday, Tuesday and Wednesday. Nonparametric tests were used as many values were below the detection limit and the distributions were skewed to the right. The associations between continuous exposure variables were analysed with Spearman correlation coefficients. The levels of sputum parameters in workers with self-reported symptoms on at least one day of exposure measurements, were compared with those without symptoms by the MannWhitney U-test. Paired comparisons of sputum parameters and lung function data on Monday and Thursday were performed by Wilcoxon signed-rank tests. Differences were considered statistically significant at $\mathrm{p}<0.05$.

\section{Results}

\section{Exposure levels}

The exposure levels to microbial agents and inhalable dust are listed in table 1. Exposure levels to endotoxins were relatively low, and only $12 \%$ of the samples were $>100 \mathrm{EU} \cdot \mathrm{m}^{-3}$ $\left(\sim 10 \mathrm{ng} \cdot \mathrm{m}^{-3}\right)$, suggested to be a no-effect level for airway inflammation [3]. Dust was intercorrelated to total bacteria (Spearman rank correlation coefficient $\left.\left(r_{s}\right)=0.7\right)$ and endotoxins $\left(r_{s}=0.6\right)$. Other intercorrelations were low $\left(r_{s}<0.3\right)$.

\section{Inflammatory cells and biomarkers in induced sputum}

Total and differential cell counts and inflammatory biomarkers in induced sputum on Monday and Thursday are shown in table 2. The percentage and concentrations of neutrophils, as well as the concentration of eosinophils and IL-8, increased significantly from Monday to Thursday. Both the increase in neutrophils and IL- 8 correlated with the increase in ECP $\left(r_{s}=0.68, p<0.01\right.$, and $r_{s}=0.62, p<0.05$, respectively). The increase in IL-8 from Monday to Thursday $(\mathrm{p}<0.05)$ and the correlation with neutrophil increase also

Table 1.-Exposure of 25 waste collectors to bacteria, fungal spores, endotoxins, $\beta_{(1-3)}$-glucans and inhalable dust

\begin{tabular}{lccc}
\hline \multirow{2}{*}{ Agents } & \multicolumn{3}{c}{ Exposure level } \\
\cline { 2 - 4 } & $\begin{array}{c}\text { Arithmetic } \\
\text { mean }\end{array}$ & Median & Range \\
& & & \\
\hline Total bacteria $\# 10^{6} \cdot \mathrm{m}^{-3}$ & 1.20 & 0.80 & $0.06-3.80$ \\
$\quad$ Rod-shaped $10^{6} \cdot \mathrm{m}^{-3}$ & 0.010 & 0.004 & $0-0.10$ \\
$\quad$ Spherical $10^{6} \cdot \mathrm{m}^{-3}$ & 1.10 & 0.80 & $0.06-3.70$ \\
$\quad$ Actinomycetes spores $10^{6} \cdot \mathrm{m}^{-3}$ & 0.03 & 0 & $0-0.40$ \\
Fungal spores $10^{6} \cdot \mathrm{m}^{-3}$ & 0.4 & 0.2 & $0-2.0$ \\
Inhalable dust $\mathrm{mg} \cdot \mathrm{m}^{-3}$ & 0.55 & 0.37 & $0.10-2.10$ \\
Endotoxins EU $\cdot \mathrm{m}^{-3}$ & 31 & 13 & $7-180$ \\
$\beta_{(1-3)}$-glucans $\mathrm{ng} \cdot \mathrm{m}^{-3}$ & 59 & 52 & $5-220$ \\
\hline
\end{tabular}

Data are presented as measures of the individual median exposures from Monday to Thursday. ${ }^{\#}$ : total bacteria, the sum of spherical and rod-shaped bacteria estimated by fluorescence microscopy, and actinomycetes spores estimated by scanning electron microscopy.
Table 2.-Percentage and concentration of nonsquamous cells and mediators in induced sputum of 21 waste collectors

\begin{tabular}{lcc}
\hline Induced sputum parameters & Monday & Thursday \\
\hline Total cells $\times 10^{6} \cdot \mathrm{mL}^{-1}$ & $1.39(0.43-7.10)$ & $2.35(0.26-11.64)$ \\
Macrophages $\times 10^{6} \cdot \mathrm{mL}^{-1}$ & $0.65(0.22-3.41)$ & $0.95(0.13-3.62)$ \\
Neutrophils $\times 10^{6} \cdot \mathrm{mL}^{-1}$ & $0.50(0.08-4.90)$ & $1.23^{*}(0.12-7.95)$ \\
Eosinophils $\times 10^{6} \cdot \mathrm{mL}^{-1}$ & $0.002(0-0.05)$ & $0.007^{*}(0-0.05)$ \\
Lymphocytes $\times 10^{6} \cdot \mathrm{mL}^{-1}$ & $0.004(0-0.28)$ & $0.005(0-0.08)$ \\
Macrophages $\%$ & $53(21-96)$ & $40(10-79)$ \\
Neutrophils \% & $46(4-75)$ & $58^{*}(22-90)$ \\
Eosinophils \% & $0.2(0-1.2)$ & $0.3(0-4.3)$ \\
Lymphocytes $\%$ & $0.2(0-1.5)$ & $0.3(0-1.5)$ \\
IL-8 ng $\cdot \mathrm{mL}^{-1}$ & $1.14(0.05-32.12)$ & $1.40^{*}(0.06-51.36)$ \\
ECP ng $\cdot \mathrm{mL}^{-1}$ & $60.9(4.8-523)$ & $71.7(8.0-1800)$ \\
\hline
\end{tabular}

Data are presented as median (range). IL: interleukin; ECP: eosinophil cationic protein. ${ }^{*}: \mathrm{p}<0.05$ significance level between Thursday and Monday (Wilcoxon signed-rank test).

maintained significance for sputum-based IL-8 standard curves $\left(\mathrm{r}_{\mathrm{s}}=0.67, \mathrm{p}<0.001\right)$.

\section{Spirometry}

Table 3 summarises the lung function variables of the waste collectors measured on Monday morning before work shift and the changes in lung function variables from Monday to Thursday. One worker was omitted because the expiration was terminated too early. Two workers showed spirometric airflow limitation.

A significant decline in FEV1 and FEV1\% of predicted values was observed from Monday to Thursday. Although the decrease in FEV1/FVC from Monday to Thursday did not reach significance $(\mathrm{p}=0.08)$, the decrease correlated with the increase in the percentage of neutrophils $\left(r_{s}=-0.51, p<0.05\right.$; fig. 1a). For the sputum-based standard curve, the increase in IL-8 from Monday to Thursday correlated with the decrease in $\mathrm{FEV} 1 / \mathrm{FVC}\left(\mathrm{r}_{\mathrm{s}}=-0.45, \mathrm{p}<0.05\right)$. Tobacco consumption in packyrs and age were also risk factors for the decline in FEV1/FVC $\left(r_{\mathrm{s}}=-0.48, \mathrm{p}<0.05\right.$, and $\mathrm{r}_{\mathrm{s}}=-0.46, \mathrm{p}<0.05$, respectively).

\section{Work-related symptoms}

The prevalence of any respiratory work-related symptom was $29 \%$, chest tightness $14 \%$ and cough with or without phlegm $10 \%$. No associations between symptoms and exposure or symptoms and induced sputum variables were found.

Table 3. - Lung function variables in waste collectors

\begin{tabular}{lcc}
\hline Lung function variables & Arithmetic mean & SD \\
\hline FEV1 \% pred & 90.1 & 10.5 \\
FVC \% pred & 99.6 & 13.4 \\
FEV $1 /$ FVC \% & 80.3 & 12.7 \\
$\Delta$ FEV1 L & $-0.12^{*}$ & 0.2 \\
$\Delta$ FEV1/FVC $\%$ & $-1.34^{* *}$ & 3.9 \\
$\Delta$ FEV1 \% pred & $-3.0^{*}$ & 4.4 \\
\hline
\end{tabular}

FEV1: forced expiratory volume in one second; \% pred: $\%$ predicted; FVC: forced vital capacity. \#: lung function on Monday morning before the work shift compared with the European Respiratory Society standard population (neversmokers, without symptoms, age 18-70 yrs); \%: difference between Thursday and Monday morning. *: $\mathrm{p}<0.05$; **: $\mathrm{p}<0.01$ (Wilcoxon signed-rank test). $\mathrm{n}=24$. 

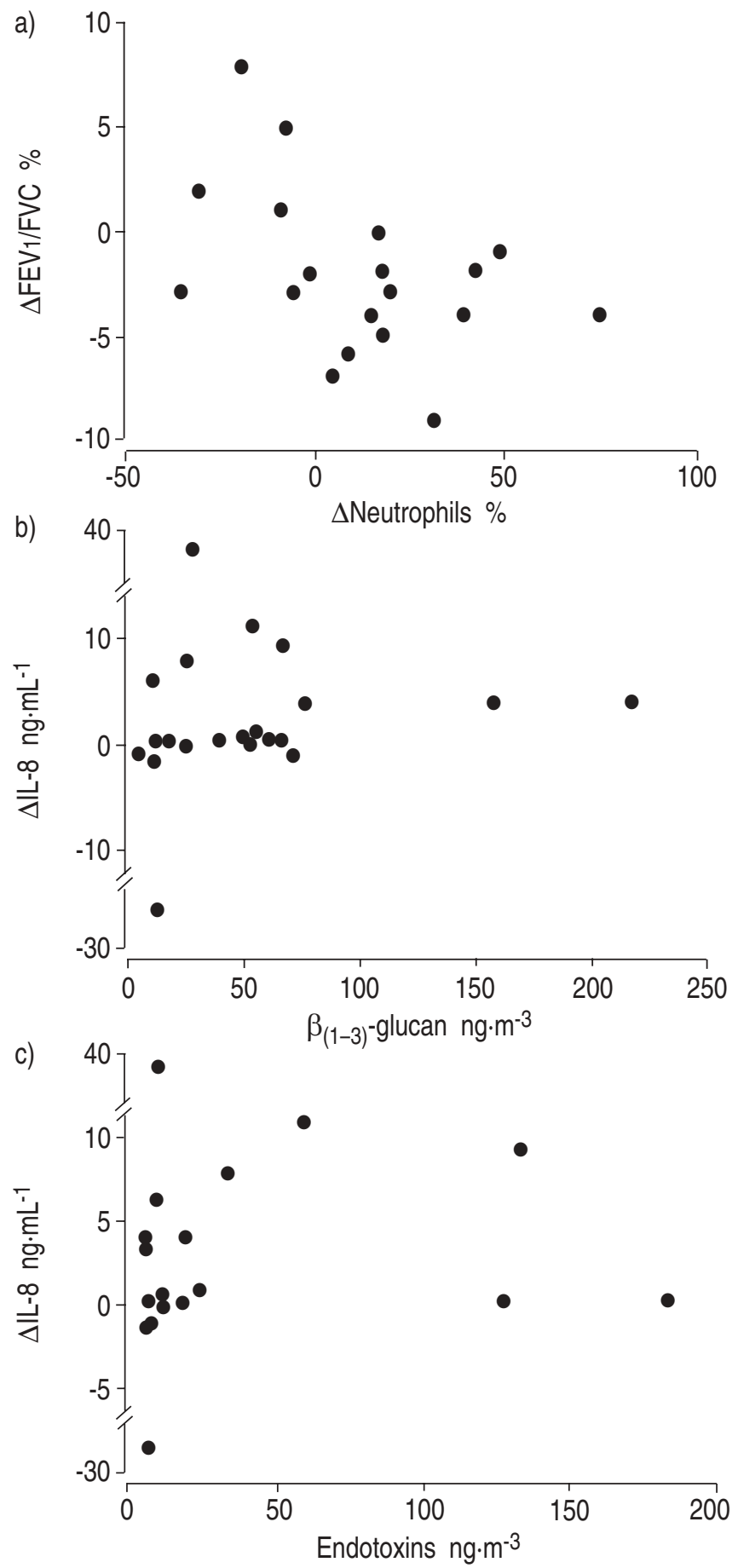

Fig. 1.-Spearman correlations $\left(\mathrm{r}_{\mathrm{s}}\right)$ between lung function, inflammatory cells and mediators in sputum and exposure. a) $\Delta$ Forced expiratory volume in one second (FEV 1 )/forced vital capacity (FVC) $\%$ and $\Delta$ neutrophils $\%$ from Monday to Thursday $\left(n=20 ; r_{s}=0.51\right.$, $\mathrm{p}<0.05)$, b) $\Delta$ interleukin (IL)-8 and median exposure levels to $\beta_{(1-3)^{-}}$ glucans from Monday to Thursday $\left(\mathrm{n}=21 ; \mathrm{r}_{\mathrm{s}}=0.38, \mathrm{p}=0.05\right)$, and $\mathrm{c}$ ) $\Delta \mathrm{IL}-8$ and median exposure levels to endotoxins from Monday to Thursday $\left(\mathrm{n}=21 ; \mathrm{r}_{\mathrm{s}}=0.55, \mathrm{p}<0.05\right)$

\section{Associations between exposure and inflammatory mediators in sputum}

The increased sputum level of IL-8 from Monday to Thursday correlated significantly with the median exposure to endotoxins $\left(\mathrm{r}_{\mathrm{s}}=0.55, \mathrm{p}<0.05\right)$ and close to significantly with the median exposure to $\beta_{(1-3)}$-glucans $\left(r_{s}=0.49, p=0.09\right.$; figs $1 b$ and $1 \mathrm{c})$. For the sputum-based standard curve, the endotoxin correlation maintained significance $\left(\mathrm{r}_{\mathrm{s}}=0.51, \mathrm{p}<0.05\right)$, while the $\beta_{(1-3)}$-glucan correlation lost significance.

\section{Discussion}

This study suggests that even moderate exposure to bioaerosols during collection of organic household waste induces a lower airway inflammation dominated by neutrophils. The increased percentage of neutrophil granulocytes in sputum from the start of work on Monday to the start of work on Thursday correlated not only with increases in the inflammatory mediators IL-8 and ECP, but also with a decrease in FEV1/FVC. The exposure during waste handling apparently induced the inflammation, since an increase in IL-8 correlated with the exposure to endotoxins and possibly $\beta_{(1-3) \text {-glucans. No associations between respiratory symptoms }}$ and inflammatory markers were found, possible due to the relatively small changes in the inflammatory response.

The sputum induction procedure itself is an inflammatory stimulus and may cause increase in inflammatory cells and mediators [20]. Therefore, a time lag from the first to the second sputum induction of $72 \mathrm{~h}$ was used, as proposed by Nightingale et al. [21] to reduce possible effects caused by the induction. Tobacco consumption may have modified the correlation between change in lung function and the percentage of neutrophils, indicating that heavy smokers may have a chronic high level of neutrophils in the lower airways. This is in agreement with earlier studies [15]. Mass significance may explain some of the associations between exposure and effects, since 40 associations were tested and two associations are likely to be found with a statistical probability of 0.05 . However, all the associations found are biologically plausible.

A comparison of the results in the present study with a study of healthy, nonsmoking, nonatopic subjects $(n=114)$ [22], suggested that sputum samples contained approximately the same number of cells, except for a higher percentage of neutrophils $(48 \%$ versus $27 \%$ ) in the waste collector workers. The low eosinophil concentration suggested a nonspecific inflammation mediated by neutrophils. A neutrophil response was further supported by an increased level of the neutrophil chemoattractant IL-8 from Monday to Thursday. Similar results have been reported recently in nasal lavage among waste collectors [5].

Although the eosinophil concentration in sputum was low, it increased significantly from Monday to Thursday in the present study. An increase in sputum eosinophils is regarded as a characteristic of asthma, but only one worker showed an eosinophil percentage $>2 \%$, suggested as a limit for eosinophilic asthma [14].

There was no significant increase in ECP from Monday to Thursday, although the change in ECP correlated with the increase in neutrophils and IL-8. Activated macrophages and neutrophils are producers of IL-8. Also, in patients with chronic obstructive pulmonary disease, an increase in neutrophils in induced sputum was related to the increase in ECP and IL-8 after inhalation of the $\beta_{(1-3)}$-glucan [23]. The results in the present study therefore suggest a neutrophil-dominated inflammatory response among the waste collectors.

In addition to a significant decrease in FEV1 from Monday to Thursday, a correlation between the decrease in FEV1/FVC and the neutrophil influx was found, indicating an acute airway obstruction caused by neutrophils.

Endotoxin exposure was associated to the increase in IL-8 from Monday to Thursday in induced sputum. The acute effects seen after human challenge with endotoxin are 
characterised by an influx of neutrophils and an increase in pro-inflammatory cytokines (IL-1, IL-6, tumour necrosis factor- $\alpha$, and IL-8) reflected in airway fluids [24]. The reason for such short-term effects on long-term changes is not clear. Chronic inflammation in the airways, as occurs in chronically exposed workers, may subsequently result in chronic respiratory symptoms and chronic loss of lung function. Several epidemiological studies of cotton workers, animal feed workers and grain handlers have shown associations between chronic decline in lung function (particularly FEV1) and exposure to endotoxin-contaminated dust [25-27].

The increase in IL-8 also tended to correlate to the $\beta_{(1-3)^{-}}$ glucan exposure. In an animal inhalation study, $\beta_{(1-3)}$-glucans did not cause neutrophilia $24 \mathrm{~h}$ after a single exposure [7]. However, in repeated exposures, endotoxin and $\beta_{(1-3)}$-glucans induced an increase in inflammatory cells in a synergistic way. Therefore, it cannot be excluded that the low levels of endotoxin in combination with $\beta_{(1-3)}$-glucan exposure during waste collection may induce an inflammatory response among the workers.

Associations between endotoxin exposure and IL-8 and MPO levels have previously been shown in nasal lavage of waste collectors and compost workers in the Netherlands [1, 5]. Thus, the inflammatory response in the nose showed similarities with the inflammatory response in the lower airways. This may be secondary to the size of causal agents as it may deposit both in the upper and lower airway. The majority of particles generated from waste have an aerodynamic diameter $>10 \mu \mathrm{m}$ [28], which are predominantly deposited in the nose and pharynx region. However, when inhaling through the mouth, e.g. during the heavy work that waste collectors carry out, larger particles also deposit in the trachea and further down.

In conclusion, exposure to bioaerosols during waste collection may induce a lower airway inflammation that can be observed in induced sputum. The inflammatory response was characterised by a neutrophil infiltration with an increased secretion of interleukin-8 from Monday to Thursday, concurrent with a decrease in forced expiratory volume in one second. These inflammatory responses showed relationships to the endotoxins and possible $\beta_{(1-3)}$-glucans exposure, but not to fungal spores and total bacteria.

\section{References}

1. Douwes J, Dubbeld H, van Zwieten L, et al. Upper airway inflammation assessed by nasal lavage in compost workers: A relation with bioaerosol exposure. Am J Ind Med 2000; 37 : $459-468$.

2. Thorn J, Beijer L, Rylander R. Airways inflammation and glucan exposure among household waste collectors. Am J Ind Med 1998; 33: 463-470.

3. Rylander R, Jacobs RR. (ICOH Committee on Organic Dust). Endotoxin in the environment: A criteria document. J Occup Environ Health 1997; 3: 1-48.

4. Nielsen EM, Nielsen BH, Breum ON. Occupational bioaerosol exposure during collection of household waste. Ann Agric Environ Med 1995; 2: 53-59.

5. Wouters IM, Hilhorst SK, Kleppe $\mathrm{P}$, et al. Upper airway inflammation and respiratory symptoms in domestic waste collectors. Occup Environ Med 2002; 59: 106-112.

6. Heldal K, Eduard W, Bergum M. Bioaerosol exposure during handling of source separated household waste. Ann Agric Environ Med 1997; 4: 45-51.

7. Fogelmark B, Sjöstrand M, Rylander R. Pulmonary inflammation induced by repeated inhalation of $\beta(1 \rightarrow 3)$-glucan and endotoxin. Int J Exp Path 1994; 74: 85-90.
8. Fogelmark B, Thorn J, Rylander R. Inhalation of $\beta(1 \rightarrow 3)$ glucan causes airway eosinophilia. Mediators Inflamm 2001; 10: $13-19$.

9. Von Essen SG, Scheppers LA, Robbins RA, Donham KJ. Respiratory tract inflammation in swine confinement workers studied using induced sputum and exhaled nitric oxide. Clinical Toxicoloy 1998; 36: 557-565.

10. Douwes J, Versloot P, Hollander A, Heederik D, Doekes G. Influence of various dust sampling and extraction methods on the measurement of endotoxin. Appl Environ Microbiol 1995; 61: 1763-1769.

11. Tamura H, Arimoto Y, Tanaka S, Yoshida M, Obayashi T, Kawai T. Automated kinetic assay for endotoxin and $(1 \rightarrow 3)$ $\beta$-D-glucan in human blood. Clin Chem Acta 1994; 226: 109112.

12. Heldal K, Skogstad A, Eduard W. Improvements in the quantification of airborne microorganisms in the farm environment by epifluorescence microscopy. Ann Occup Hyg 1996; 4: 437-447.

13. Eduard W, Sandven P, Johansen B, Bruun R. Identification and quantification of mould spores by scanning electron microscopy (SEM). Ann Occup Hyg 1988; 32: 447-455.

14. Pin I, Gibson PG, Kolendowicz R, et al. Use of induced sputum cell counts to investigate airway inflammation in asthma. Thorax 1992; 1: 25-29.

15. Pizzichini E, Pizzichini M, Efthimiadis A, et al. Indices of airway inflammation in induced sputum: reproducibility and validity of cell and fluid-phase measurements. Am J Respir Crit Care Med 1996; 154: 308-317.

16. Gardner RM, Hankinsom JL, Crapo RO, Johnson RL, Epler GR. Standardization of spirometry-1987 update. American Thoracic Society. Am Rev Respir Dis 1987; 16: 1285-1298.

17. European Respiratory Society. Standardised lung function testing. Eur Respir J 1993; 6: Suppl. 16, 25-32.

18. British Thoracic Society. Guidelines for the management of chronic obstructive pulmonary disease. Thorax 1997; 5: $1-26$.

19. Melbostad E, Eduard W. Organic dust-related respiratory and eye irritation in Norwegian farmers. Am J Ind Med 2001; 39: 209-217.

20. Holz O, Richter K, Jörres RA, Speckin P, Magnussen H. Changes in sputum composition between two inductions performed on consecutive days. Thorax 1998; 28: 284-292.

21. Nightingale JA, Rogers DF, Barnes PJ. Effect of repeated sputum induction on cell counts in normal volunteers. Thorax 1998; 53: 87-90.

22. Spanevello A, Confalonieri M, Sulotto F, et al. Induced sputum cellularity. Am J Respir Crit Care Med 2000; 162: 1172-1174.

23. Yamamoto $\mathrm{C}$, Yoneda $\mathrm{T}$, Yoshikawa $\mathrm{M}$, et al. Airway inflammation in COPD assessed by sputum levels of interleukin 8. Chest 1997; 112: 505-510.

24. Thorn J. The inflammatory response in humans after inhalation of bacterial endotoxin: a review. Inflamm Res 2001; 50: 254-261.

25. Kennedy SM, Christiani DC, Eisen EA, et al. Cotton dust and endotoxin exposure-response relationship in cotton textile workers. Am Rev Respir Dis 1987; 135: 194-200.

26. Smid T, Heedrik D, Houba R, Quanjer P. Dust and endotoxin related respiratory effects in the animal feed industry. Am Rev Respir Dis 1992; 146: 1474-1479.

27. Schwartz DA, Thorne PS, Yagla SJ, et al. The role of endotoxin in grain dust-induced lung disease. Am J Respir Crit Care Med 1995; 152: 603-608.

28. Breum NO, Nielsen EM, Nielsen BH. Waste collectors' bioaerosol exposure in collecting garden waste in bins. Report number 1. Copenhagen, National Institute of Occupational Health, 1995. 